\title{
Osteopetrosis and related disorders
}

INSERM

\section{Source}

INSERM. (1999). Orphanet: an online rare disease and orphan drug data base.

Osteopetrosis and related disorders. ORPHA:2781

Osteopetrosis, also known as marble bone disease, is a descriptive term that refers to a group of rare, heritable disorders of the skeleton characterized by increased bone density on radiographs. 